\title{
Left Atrial Myxoma Presenting As a Stroke - An Unusual Case Scenario
}

\author{
Mounika Pinninti ${ }^{1}$, B.Syandhika ${ }^{1}$,Kasturi Ravinder Reddy ${ }^{2}$, Nikhil Mudgalkar $^{3}$, Ashish Baviskar $^{4}$
}

1. Junior resident in Department of General medicine, Prathima institute of medical sciences, NagnurRoad, Karimnagar

2.Professor and Head of department of Medicine and consultant cardiologist,Prathima institute of medical sciences, NagnurRoad,Karimnagar

3. Professor, Departmentof Anesthesia, Prathima institute of medical sciences, Nagnur Road, Karimnagar 4.Head of department,Department of Cardiothoracic and Vascular Surgery

Corresponding author: Dr.K.RavinderReddy, Professor and Head of department of Medicine and consultant cardiologist, Prathima institute of medical sciences, Nagnur Road, Karimnagar

Email:rrkasturi@gmail.com

Submission: 22/1/2021

Review:5/2/2021

Acceptance: 27/3/2021

DOI:10.47799/pimr.0901.17

\section{ABSTRACT}

The most common benign cardiac tumor is cardiac myxoma,accounting for around $50 \%$ of all primary cardiac tumors. Cardiac myxoma is an uncommon cause ofcardioembolic stroke.Overall,cardioembolic stroke accounts for approximately $30 \%$ of all ischemic stroke of which $0.5 \%$ of cardioembolic strokes are attributable to a cardiac myxoma.It has an annual incidence of around 0.5 cases per one million people with female predominance.

Early diagnosis is necessary to prevent its devastating complications such as embolic stroke and sudden cardiac death.We present a relatively rare case of an acute stroke as a first and only manifestation of an atrial myxoma.

\section{Introduction:}

Left atrial myxoma is a rare diagnosis even in tertiary care cardiac centre. A myxoma is a benign heart tumour that is very rare $^{1,2,3}$. Myxomata are the most common primary cardiac tumour in adults, and they are most commonly located near the Fossa ovalis in the left atrium ${ }^{4,5,6}$. Other heart chambers can also grow myxomata. Multipotent mesenchymal cells give rise to the tumour. Cardiac myxoma affects people between the ages of 30 and $60^{7,8}$. We came across a case where the primary symptom was neurological, and the final diagnosis was made after further examination. Because of the variety of presentations, diagnosis can be difficult, and transthoracic echo is the modality of choice. We present a case in which the primary presenting symptom was a stroke, and upon examination, a diagnosis of left atrial myxoma was made.

\section{CASE DESCRIPTION}

A 40 year old male with no past medical history was admitted in the Department of Medicine in our hospital with chief complaints of weakness of left upper limb and lower limb, and slurring of speech since one day.The patient was asymptomatic 1 day back then he suddenly developed weakness of left upper limb and lower limb associated with slurring of speech. Patient had no past and family history of cardiovascular disorders. At the time of admission, he was conscious, and had a Pulse rate of $88 / \mathrm{min}$, Blood pressure $120 / 70 \mathrm{mmhg}$, respiratory rate of $18 /$ min and oxygen saturation was maintained. Neurological examination revealed left hemiparesis with left upper and lower limb power of $1 / 5$ with increased tone. Reflexes were brisk bilaterally and left plantar response was extensor.Clonus was not present. Higher mental functions were normal.Cardiac auscultation revealed a mid-diastolic murmur,and it was heard with postural variation.Chest was clear on auscultation.

ECG showed sinus rhythm with left atrial enlargement.CT BRAIN revealed hypodensity in right frontoparietal region corresponding to right MCA territory suggestive of acute infarct. (Figure 1) 
Transthoracic echo cardiogram showed an echogenic pedunculated mass in left atrium of size $5.2 \mathrm{~cm} \times 3.8 \mathrm{~cm}$, Attached to interatrial septum, highly suggestive of atrial myxoma.(fig 2)

The patient was recovering well and arranged to discharge 14 days after the stroke. He underwent an excision of the myxoma in cardiothoracic surgery department of our hospital .The cytopathological analysis of the mass revealed it to be benign atrial myxoma.No postoperative complications were observed

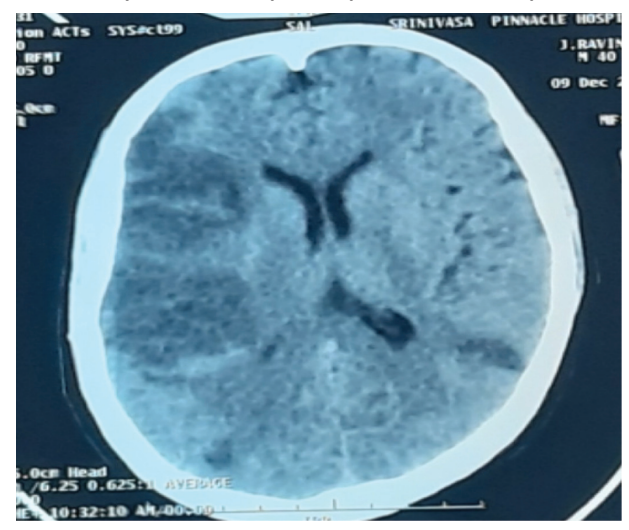

Fig1.CT BRAIN showing acute infarct in right Fronto-Parietal region

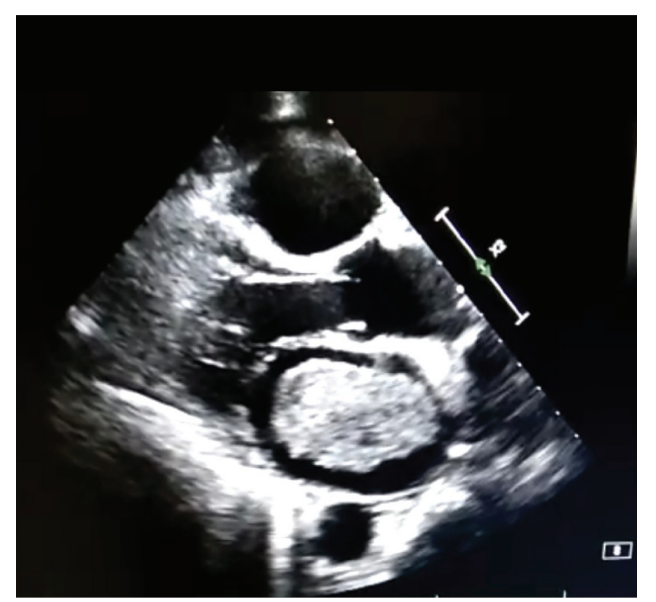

Fig 2.Transthoracic Echocardiography Showing a left atrial mass attached to IAS, highly suggestive of LAmyxoma

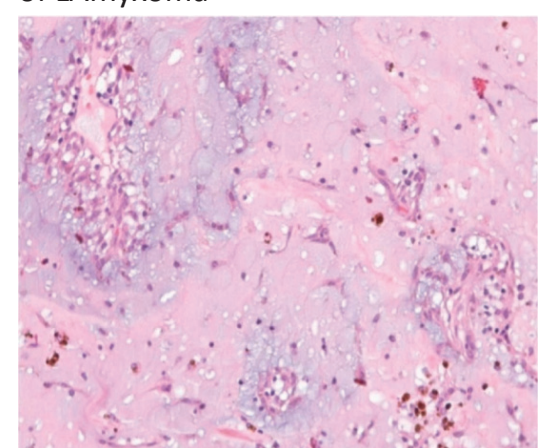

Histopathology showing stellate cells, in a fibro-myxoid stroma typical of a myxoma.

\section{DISCUSSION}

We present this case to increase awareness and to stress at early evaluation of secondary causes of ischemic CVA, outside the realm of hypercoagulability ${ }^{9,10}$.

Atrial myxomas are the most common primary tumor of the heart.It has female predominance of ratio 2:1,involving age group of 30-60 years.Although the most common cause of cardiac tumor is metastasis from other site.Approximately $90 \%$ of myxomas are sporadic and remaining are familial, and may occur as a part of familial syndromes. One of which is the carney complex which includes cardiac and mucocutaneous myxomas, schwannomas, endocrine hyperactivity and pigmented skin lesions.Approximately, $85-90 \%$ of myxoma is originated from left atrium followed by right atrium,right and left ventricle,respectively. Embolism occurs in about $30-40 \%$ of patients with myxoma ${ }^{11,12}$.

Cardiac myxoma is an endocardial neoplasm resulting from mesenchymal stem cell dysregulation.They arise from subendocardium, are often pedunculated and the majority occur in the left atrium.Some patients are asymptomatic and the tumor is incidentally detected on cardiac imaging. However, patients usually present with either dyspnea,chestpain, syncope, palpitations or constitutional symptoms such as fever(Pyrexia of unknown origin), malaise, arthralgias, weightloss, rash etc.Some myxomas have extensive calcification and have thrombi on the tumor surface which can embolize. ${ }^{13}$

The presence of embolic phenomena,especially in young patients with neurological symptoms, should prompt early neuro and cardio imaging even in the absence of electrocardiographic or auscultation abnormalities. ${ }^{14,15}$

The diagnostic method of choice is $2 \mathrm{D}$-echocardiography.In the diagnosis of left atrial myxoma, Transthoracic echocardiography(TTE) has a sensitivity of around $90 \% 16$. Cardiac MRI can assist in delineating tumor size,attachment and mobility.For left-sided tumors, resection is recommended because of risk of embolization. Operative mortality is less than $1 \%$ and risk of recurrence is around $5 \%$,requiring the need for cardiacfollow up.

\section{CONCLUSION}

The diagnosis of atrial myxoma can be elusive,especially when the symptoms suggest a systemic illness. Thepatient we reported did not experience any symptoms before stroke and had no common stroke risk factors such asdiabetes, hypertension, hypercholesterolemia, obesity and atrial fibrillation. In such patients, the possibility of cardiac myxoma causing ischemic stroke should be highly suspected.Echocardiography is the first choice for the diagnosis of cardiac myxoma and surgery is the treatment of choice. 


\section{REFERENCES}

1. Reynen K. Cardiac myxomas. N Engl J Med 1995;333:16107.

2. Allard MF, Taylor GP, Wilson JE, McManus BM. Primary cardiac tumors. In: Goldhaber SZ, Braunwald E, editors. Cardiopulmonary Diseases and Cardiac Tumors: Atlas of Heart Diseases. Philadelphia: Current Medicine; 1995. p. 15.1-15.22.

3. Colucci WS, Schoen FJ. Primary tumors of the heart. In: Braunwald E, Zipes DP, Libby P, editors. Heart Disease. A Textbook of Cardiovascular Medicine. 6thed. Philadelphia: W. B. Saunders Co.; 2001. p. 1807-22.

4. Percell RL Jr, Henning RJ, Siddique Patel M. Atrial myxoma: Case report and a review of the literature. Heart Dis 2003;5:224-30.

5. MacGowan SW, Sidhu P, Aherne T, Luke D, Wood AE, Neligan MC, et al. Atrial myxoma: National incidence, diagnosis and surgical management. Ir J Med Sci 1993;162:223-6.

6. Ekinci El, Donnan GA. Neurological manifestations of cardiac myxoma: A review of the literature and report of cases. Intern Med J 2004;34:243-9.

7. Pinede L, Duhaut P, Loire R. Clinical presentation of left atrial cardiac myxoma. A series of 112 consecutive cases. Medicine (Baltimore) 2001;80:159-72.

8. Mendoza CE, Rosado MF, Bernal L. The role of interleukin6 in cases of cardiac myxoma. Clinical features, immunologic abnormalities, and a possible role in recurrence. Tex Heart Inst J 2001;28:3-7.

9. Keeling IM, Oberwalder P, Anelli-Monti M, Schuchlenz H, Demel U, Tilz GP, et al. Cardiac myxomas: 24 years of experience in 49 patients. Eur J Cardiothorac Surg 2002;22:971-7.

10. Braunwald E, Zipes DP, Libby P. Heart Disease: A Textbook of Cardiovascular Medicine. 6thed. Philadelphia: WB Saunders; 2001.

11. Mu“gge A, Daniel WG, Haverich A, Lichtlen PR. Diagnosis of noninfective cardiac mass lesions by two-dimensional echocardiography. Comparison of the transthoracic and transesophageal approaches. Circulation 1991;83:70-8

12. Yuan S-M, Humuruola G. Stroke of a cardiac myxoma origin. Rev Bras Cir Cardiovasc 2015; 30:225-348

13. He D-K, Zhang Y-F, Liang Y, Ye S-X, Wang C, Kang B, et al. Risk factors for embolism in cardiac myxoma: a retrospective ana- lysis. Med Sci Monit2015; 21:1146-54.
14. Singh SD, Lansing AM. Familial cardiac myxoma-a comprehensive review of reported cases. J Ky Med Assoc 1996; 94: 96-104.

15. Mir IA, Ghani Ahangar A. Atrial myxoma: a review. Int J Community Med 2016; 3:23-9.

16. Lee KS, Kim GS, Jung Y, Jeong IS, Na KJ, Oh BS, et al. Surgical re- section of cardiac myxoma-a 30-year single institutional ex- perience. J Cardiothorac Surg 2017; 12:18.

How to cite this article : Pinninti M, B.Syandhika,Kasturi RR,Mudgalkar N, Baviskar A. Left Atrial Myxoma Presenting As a Stroke - An Unusual Case Scenario. Perspectives in Medical Research 2021; 9 (1):84-86

DOI:10.47799/pimr.0901.17

Sources of Support: Nil, Conflict of interest: None declared 